\title{
La tercera persona: una propuesta antropológico-filosófica delimitada frente al planteamiento sociológico
}

\section{(The third person: a philosophical- anthropological proposal contrasted with the sociological approach)}

\author{
Natalia S. GARCía PÉREZ
}

Recibido: 20 de diciembre de 2013

Aceptado: 5 de octubre de 2015

\section{Resumen}

Frente al paradigma diádico preponderante en la teoría social, recientes propuestas reivindican la función del tercero. En estas teorías, el tercero personaliza el orden social normativo -surgido en la relación diádica- y atribuye empíricamente el reconocimiento como persona. Frente a este planteamiento empírico, proponemos un enfoque trascendental antropológico-filosófico, según el cual la estructura tri-posicional de las relaciones sociales constituye la condición de posibilidad de la cultura normativa y del modo de ser propio del hombre en cuanto que persona.

Palabras clave: el tercero, persona, planteamientos empírico y trascendental, presencia y ausencia, subjuntivo, normas, temporalidad, historicidad, producción.

\begin{abstract}
Recent approaches in social theory stress the significance of the third against the dominance of the dyadic paradigm. Arising in the dyad, the social normative order is objectified and thereafter personalized by the third, who also empirically attributes the recognition as person. Contrasting with this empirical standpoint, I propose a philosophical-anthropological approach according to which the tri-positional
\end{abstract}


structure of sociality constitutes the transcendental condition of possibility of culture and of the "way of being" of the human being as person.

Keywords: the Third, person, empirical and transcendental approaches, presence and absence, subjunctive, rules, temporality, historicity, production.

\section{Introducción}

Frente a la filosofía moderna del sujeto, el siglo XX se abrió con la puesta de relieve de la significación fundante de la subjetividad ajena, del otro de carne y hueso, del tú con quien dialogo, que me apela y a quien me dirijo, para con quien tengo una responsabilidad y con quien constituyo un mundo en común. Este descubrimiento trastocaba la comprensión del modo de ser del hombre y de su relación con el ente, haciendo necesaria una nueva ontología intrínsecamente histórica vinculada a su vez con el modo comprensivo de abrirse al mundo por parte del hombre - una concepción de la que Dilthey sentó fecundamente los primeros cimientos. El problema de la alteridad no sólo marcaba el rumbo de la filosofía, sino que asimismo determinaba a la naciente disciplina sociológica, que ponía como fundamento del orden social la relación entre dos individuos, concebida de diversos modos.

Con todo, ya desde la Sociología de 1908 de Georg Simmel, que pasa por ser una de las obras fundacionales de la disciplina y, en filosofía, al menos desde Sartre y Lévinas, junto al otro o a la díada aparecía, aunque fuera de un modo secundario y subordinado, la figura de un tercero que modificaba de diversos modos la relación diádica de partida 1 . Partiendo de las reflexiones de éstos y de otros filósofos y sociólogos -más o menos marginales o fragmentarias en sus obras-diversos sociólogos y filósofos sociales han venido reivindicando en los últimos años la necesidad de consumar un "giro" (Fischer 2010) conducente a un "nuevo paradigma" triádico que sustituya al paradigma diádico vigente hasta ahora en las ciencias sociales (Koschorke 2010).

Las contribuciones sobre este tema, muchas de las cuales forman parte de volúmenes colectivos íntegramente dedicados al $\mathrm{mismo}^{2}$, evidencian una gran diversidad en sus planteamientos y en su alcance teórico. En este trabajo nos centraremos exclusivamente en las contribuciones teórico-sociales, no ya con el objetivo de hacer un inventario completo de ellas o de sistematizarlas de acuerdo a su propio

\footnotetext{
1 Para un recorrido histórico sumario pero completo del problema de la intersubjetividad, incluyendo los "fragmentos sobre el tercero", véase Fischer (2000).

2 Eßlinger [et al.] (2010) y Bedorf [et al.] (2010) abordan el problema desde una perspectiva teóricosocial. Desde una perspectiva filosófica, véase el siguiente monográfico de la revista Archivio di Filosofia: VV.AA. (2006).
} 
punto de vista -entendiendo por tal el inmanente a la propia disciplina sociológica-, sino con el de proponer, delimitándolo frente al planteamiento teórico-social, un planteamiento esta vez antropológico-filosófico del problema del tercero, y de mostrar su necesidad partiendo del mismo enfoque teórico-social ${ }^{3}$.

\section{El límite interno del planteamiento empírico de la función del tercero en la teoría social y la necesidad de un planteamiento trascendental antropológi- co-filosófico}

\subsection{De la interacción a la institución: la "objetivación" de la norma surgida en la relación diádica}

Encontramos claramente definido el que podríamos denominar el planteamiento "clásico" de la función del tercero en la obra de 1926 de Theodor Litt Individuo y comunidad y, sobre todo, en La construcción social de la realidad de Peter L. Berger y Thomas Luckmann, publicada en el año 1967. En ambos casos, el orden social normativo surge en la relación diádica, reduciéndose la función del tercero a separarlo de ella, dotándolo así de independencia (Fischer 2006, p. 154).

Theodor Litt (1926) introduce el "fenómeno fundamental del "tercero"” (p. 237) en el tercer capítulo de su obra, que lleva por título "El círculo cerrado", tras haber dedicado el capítulo inmediatamente anterior a la discusión de la relación entre el yo y el tú, caracterizada por la reciprocidad y la comunicación simbólica. La estructura específica que es el "círculo cerrado" se alcanza, según Litt, cuando el yo se encuentra en relación con un tú y con otro tú que a su vez aparecen en su horizonte como relacionados por su parte entre sí. Así, cuando el yo sólo se relaciona con el tú -o con un número indefinido de ellos que no se encuentran por su parte relacionados entre sí-, los símbolos que éste utiliza se encuentran tan ligados a su expresión individual propia que el yo no puede representárselos como algo objetivo que fuera en sí independiente respecto de dicha expresión. Esta situación cambia radicalmente cuando, con la inclusión del tercero, "el mismo simbolismo consigue determinación y fijación en el ser anímico-corporal de seres distintos", en la medida en que, con ello, "la 'unión personal' que vincula el símbolo a un productor humano determinado se encuentra lo suficientemente distendida como para que

\footnotetext{
${ }^{3}$ Entendemos aquí por teoría social aquella parte de la sociología que se ocupa de los procesos de constitución del orden social en las relaciones sociales, esto es, de cómo a partir de lo "social" se constituye la "sociedad". Partiendo de su estudio histórico ( $c f$. supra), Joachim Fischer (2006 y 2010) ha sistematizado cuatro argumentos en favor de la consideración de la figura del tercero por parte de la teoría social. De ellos, nos centraremos aquí en el que incide en la idea de que en las teorías sociales diádicas existiría un "missing link" entre la interacción y la institución -que sería el argumento propiamente teórico-social.
} 
la forma y el sentido puedan de verdad presentarse claramente en su estar por encima de la persona" (p. 240. Tr. propia).

De este modo, como se ve, el símbolo ya existe en la relación entre el yo y el tú, reduciéndose la función del tercero a su separación respecto de la expresión individualmente determinada de la persona concreta. Litt presenta por tanto al tercero como la condición para la objetivación del símbolo (p. 241), pero no afirma que lo constituya ni en cada caso particular ni como tal, es decir, en su condición de símbolo. Del mismo modo, tampoco le reconoce una función constitutiva respecto de la reciprocidad con la que inicialmente había caracterizado a la relación diádica entre el yo y el tú.

El problema que entraña esta concepción se hará patente en la propuesta de Berger y Luckmann. Como le había ocurrido a Litt con los símbolos, estos autores se dan cuenta de que hacer surgir el orden normativo en la relación social diádica presenta una dificultad que sólo puede resolverse recurriendo a un tercer actor. Sin embargo, en el modo como lo introducen, únicamente consiguen hacer más evidente esa misma dificultad.

Según Berger y Luckmann (2011), toda actividad humana, incluso la de un "hipotético individuo solitario", estaría sujeta a una habituación consistente en el establecimiento de pautas conforme a las cuales regirse en lo sucesivo (pp. 72-73). Sobre estos procesos de habituación se constituiría la institución en la interacción entre dos individuos, al atribuirse éstos recíprocamente determinadas pautas de comportamiento, fijándolas tanto a las acciones como a los tipos de actores que hayan de desempeñarlas (pp. 74-78). Así, una determinada acción individual caerá bajo un determinado tipo y deberá regirse por lo que establezca ese tipo, a la vez que deberá ser desempeñada por un determinado tipo de actor, el cual representará con ello un rol. De esta suerte, la institución queda definida como "una tipificación recíproca de acciones habitualizadas por tipos de actores" (p. 74). Las instituciones, así definidas, "controlan el comportamiento humano estableciendo pautas definidas de antemano que lo canalizan en una dirección determinada", esto es, lo normativizan (p. 74).

Ahora bien, la dificultad que se les presenta a Berger y Luckmann es que la institución, en cuanto que nacida en la interacción diádica, parecería resultar dependiente de la inmediatez del "aquí y ahora" que caracteriza a la situación "cara a cara" (pp. 44 ss.). Por ello, restringen inicialmente su alcance, afirmando que en la relación diádica la institucionalización tendría lugar sólo "in nucleo" (p. 77), al encontrarse las normas sociales inmediatamente ligadas a su seguimiento por parte de sus creadores personales, pudiendo por principio resultar alteradas en cualquier momento. Los productos de la actividad humana, sin embargo, han de servir "como índices más o menos duraderos de los procesos subjetivos de quienes los producen, lo que permite que su disponibilidad se extienda más allá de la situación 'cara a 
cara' en la que pueden aprehenderse directamente" (p. 50. La cursiva es nuestra). Es esta duración más allá del "aquí y ahora" propio de la interacción diádica la que va a quedar garantizada gracias al tercero, en la medida en que éste, al adoptar las normas del tú y el yo, las separa de ellos, dotándolas así de objetividad:

Las habituaciones y tipificaciones emprendidas en la vida común de A y B, formaciones que hasta este momento aún conservaban la cualidad de concepciones $a d$ hoc de dos individuos, se convierten ahora en instituciones históricas. Al adquirir historicidad, estas formaciones adquieren también otra cualidad crucial, o, más exactamente, perfeccionan una cualidad que existía en germen desde que A y B iniciaron la tipificación recíproca de su comportamiento: la objetividad (p. 78).

Pero entonces, ¿adquieren la cualidad de la objetividad o la perfeccionan? El problema es que la norma como norma, en su condición normativa, contiene ya en sí la validez para un número indefinido de casos que puedan caer bajo ella, y por tanto lleva implícita en su estructura una trascendencia más allá del aquí y el ahora. En cuanto que norma, no vale sólo aquí y ahora, en este momento preciso, no se pliega a la acción individual hasta coincidir con ella y depender inmediatamente de ella, ni tampoco a este actor determinado individualísimo, sino a cualesquiera actores que cumplan los criterios establecidos por ella, que caigan bajo un tipo. De surgir en la relación diádica, surgiría por tanto trascendiendo ya, por su propia condición de norma, el aquí y ahora. Por ello, Berger y Luckmann se ven obligados a corregirse: la cualidad de la objetividad-que implica la trascendencia más allá del aquí y ahora- ya existe en la interacción diádica, limitándose la función del tercero a perfeccionarla. Con esto, dan al traste con su intuición fundamental, la de que la trascendencia más allá del aquí y ahora de las normas tuviera que ver con una tercera instancia; al tiempo que dejan en pie, incólume, el problema de fondo por el que el que habían sentido la necesidad de recurrir al tercero, pues: ¿cómo es posible que en el aquí y ahora de la interacción diádica surja algo que por su estructura propia trasciende ese aquí y ahora?

De este modo, la función del tercero en el planteamiento de Berger y Luckmann induce a engaño. El problema del que ellos quieren ocuparse no es el de la constitución de las normas como normas, sino el de su surgimiento empírico. Por ello, su experimento mental consiste en abstraer una relación social diádica respecto de cualquier orden social determinado previo, esto es, respecto de cualquier norma particular dada -se trataría de la situación que se daría, por ejemplo, en la interacción entre un Robinson y un Viernes, que comienzan a crear instituciones de novo porque no comparten ninguna norma o tipificación, viniendo como vienen de órdenes sociales completamente diferentes (pp. 75-76). En realidad, con esta abstracción, lo que Berger y Luckmann están haciendo es representarse la situación empírica más básica que satisface las condiciones de su propia definición de "institu- 
ción" -recordémoslo: "una tipificación recíproca de acciones habitualizadas por tipos de actores". Partiendo de esta definición, la figura de un tercero resultaba $a$ priori innecesaria.

Y, sin embargo, pudiera aun asi parecer que Berger y Luckmann sí le han otorgado al tercero la función -nada despreciable- de hacer posible la trascendencia de las normas sociales más allá del aquí y ahora de la interacción diádica; esto es, parece como si hubieran en efecto logrado solucionar el problema de partida. Además de lo intrincado del asunto, la propia redacción sirve a mantener esa ambigüedad, como se ve en la cita que hemos traído a colación poco más arriba. Ahora bien, la razón última de que Berger y Luckmann no pudieran resolver este problema radica en el hecho de que para hacerlo se habrían visto obligados a trascender los límites de inmanencia de su propia disciplina, en la medida en que el problema de la constitución de las normas como normas no es un problema teórico-social sino filosófico.

Sólo cuando hemos apreciado de esta manera cómo la ambigüedad de la función del tercero en el planteamiento de Berger y Luckmann tiene que ver con una "distribución de tareas" entre disciplinas, podemos darnos cuenta de que dicha ambigüedad se asienta a su vez sobre otra que afecta en términos generales a la concepción que estos autores tienen de la constitución o el surgimiento del orden social. En efecto, Berger y Luckmann se habían visto necesitados de hacer preceder el apartado intitulado "Orígenes de la institucionalización" -en el que se tratan las cuestiones que hemos visto-, por un apartado netamente antropológico-filosófico que llevaba por título "Organismo y actividad". La relación que se establece entre ambos apartados sirve a crear una apariencia y a la vez una confusión -enteramente en consonancia con lo que hasta aquí hemos visto- según la cual parece que se aborde aquello que en realidad se hurta: el problema filosófico-trascendental de la constitución del orden social.

En el apartado "Organismo y actividad", Berger y Luckmann fundamentan la "necesidad" del orden social en "el equipo biológico del hombre" (p. 72). Los instintos humanos serían sumamente inespecíficos, lo que significaría una fundamental "apertura al mundo" opuesta a los "mundos cerrados cuyas estructuras están predeterminadas por el capital biológico de las diversas especies animales" (pp. 6465). La "estabilidad del orden humano que existe empíricamente" derivaría de su transformación "por el orden social en una relativa clausura al mundo" (p. 70). Por consiguiente, "cabe formular la pregunta en otro plano. Podemos preguntarnos de qué manera surge el propio orden social" (p. 71). La respuesta que Berger y Luckmann dan a esta pregunta por ellos mismos formulada es la de que "el orden social es un producto humano, o, más exactamente, una producción humana constante, realizada por el hombre en el curso de su continua externalización" (p. 71). Ahora bien: 
Si bien los productos sociales de la externalización humana tienen un carácter sui generis en oposición al contexto de su organismo y de su ambiente, importa destacar que la externalización en cuanto tal constituye una necesidad antropológica. (...) La inestabilidad inherente al organismo humano exige como imperativo que el hombre mismo proporcione un contorno estable a su comportamiento; él mismo debe especializar y dirigir sus impulsos. (...) [A] unque ningún orden social existente pueda derivar de datos biológicos, la necesidad del orden social en cuanto tal surge del equipo biológico del hombre (pp. 71-72).

Ahora bien, al margen de lo muy dudoso de esta necesidad - en cuanto que fundada en un presunto equipo biológico inespecífico del hombre lógicamente previo al propio orden social-, la cuestión es que mostrar que algo era necesario no es lo mismo que dar razón de cómo su estructura normativa propia - de la que por lo demás nada se dice-pudo llegar a constituirse. ¿Cuál es ese carácter "sui generis" del orden social y cómo puede llegar a constituirse en su carácter "sui generis"?

Nuevamente podría decirse que no es éste el problema de Berger y de Luckmann. Pero ya la cosa no es tan sencilla. La sucesión de los dos apartados, el antropológico-filosófico y el teórico-social, exige que sí sea su problema. Precisamente por no hacerlo su problema, se genera la característica confusión a la que nos referíamos. Pues el apartado antropológico-filosófico estaría precisamente en el lugar de la indagación filosófico-trascendental que el apartado siguiente sobre los "orígenes de la institucionalización" no necesitaría abordar ya, dado su enfoque empírico. Sin embargo, al mismo tiempo, en la medida en que ese primer apartado antropológico-filosófico no ha realizado de hecho esa indagación - no se ha ocupado de dar cuenta de la constitución de ese carácter "sui generis" del orden social como tal-, el apartado sobre los "Orígenes de la institucionalización", que lo sucede sin solución de continuidad, viene a ocupar o sustituir la indagación filosóficotrascendental que no se ha realizado en el primero; parece, en efecto, como si en este segundo apartado sí se tratara de la constitución del orden social normativo, cuya necesidad -y sólo ella- había sido puesta de manifiesto por su parte en el primer apartado antropológico-filosófico. De esta suerte, el segundo apartado sobre los "Orígenes de la institucionalización” queda dispensado de la indagación filosóficotrascendental gracias al primero, a la vez que este primer apartado antropológicofilosófico queda dispensado de hacer esa misma indagación gracias al segundo, al que parece quedar remitido.

La distribución de tareas entre disciplinas era entonces sólo aparente y servía únicamente a ocultar la ausencia de una indagación acerca de la estructura normativa propia del orden social. Es esta misma ambivalencia la que se traslada a la propia función del tercero en el apartado segundo, al que no se le reconoce una función en la constitución de las normas como normas porque ése no es el problema-el problema es empírico, no filosófico-trascendental-, pero, al mismo tiempo, parece 
como si, con todo, si se le reconociera la función de hacer posible la trascendencia de las normas más allá del aquí y ahora -la cual es intrínseca a las propias normas, y remite por tanto al problema filosófico-trascendental de su constitución.

Una consecuencia ulterior del planteamiento empírico de la función del tercero se pone de manifiesto en las dos propuestas recientes en las que nos centraremos aquí, las de Gesa Lindemann y Volker Schürmann.

\subsection{La atribución empírica del reconocimiento como persona}

Según Lindemann (2010), Berger y Luckmann pueden presentar a la díada como punto de partida de lo social en cuanto que manejan la "presuposición antropológica" de que los actores sociales de la díada son actores sociales legítimos en cuanto que son humanos. Ahora bien, justamente en esa legitimidad de los actores de la relación diádica estaría ya supuesta la tercera persona (p. 168). Así, mientras que en Berger y Luckmann el tercero tendría una función de mera "emergencia" del orden social a partir de la interacción diádica, Lindemann se propone mostrar cómo la función del tercero sería en realidad "constitutiva": el tercero constituiría a la díada en cuanto que sólo por su intermedio se determinaría la legitimidad de los actores sociales como tales actores sociales y, con ello, el carácter específicamente social de su interacción (pp. 162 y 168ss.).

Con su "presuposición antropológica", Berger y Luckmann estarían determinando a priori cuáles son las entidades que están legitimadas como actores sociales, cuando esta determinación tendría lugar en realidad, según Lindemann, empíricamente, desde las propias relaciones sociales en cuanto que triádicas. Así, el tercero establecerá, conforme a las normas particulares de un orden social empírico dado, si una determinada entidad cualifica o no como actor social en sentido absoluto $^{4}$. Esto significa $-\mathrm{y}$ esto es lo que le interesa subrayar a Lindemann- que un actor Ego no puede reconocer o sustraer el reconocimiento a un actor Alter arbitrariamente, conforme a su puro antojo individual, ya que esta relación diádica EgoAlter se encuentra siempre controlada por una posición Tertius, que obliga a Ego a configurar su reconocimiento con una validez que sea generalizable -siempre en función de lo establecido en el orden social de que se trate (p. 179)5.

Lindemann deduce esta función del tercero a partir de un estudio empírico realizado en una unidad de rehabilitación neurológica. En esta unidad, los pacientes se encuentran en un estado neurológico crítico, hasta el punto de que se duda de si son o no capaces de interaccionar socialmente. En su trato con ellos, los terapeutas tienen que llegar a establecer si son capaces de utilizar símbolos y, para empezar, si

\footnotetext{
4 Esto es, como actor social que está dentro del orden de que se trate o como otra $\cos a$, que no es actor social, que queda fuera de él, y de la que se podrá por tanto disponer como esté previsto para todas aquellas entidades que no se consideren legitimadas como actores sociales.

5 Véase asimismo Schürmann (2010), p. 81.
} 
responden a preguntas que se les formulen con gestos que signifiquen afirmación o negación. Ahora bien, para poder llegar a establecer que el paciente es capaz de utilizar símbolos, así como, en particular, qué gestos concretos del paciente pueden o no ser interpretados en cada caso como símbolos, en la unidad clínica estudiada por Lindemann no basta la apreciación de un único terapeuta, sino que se precisa siempre la confirmación de un segundo terapeuta, el cual ocuparía una tercera posición Tertius respecto de la relación diádica entre Ego, que sería el primer terapeuta, y Alter, que sería el paciente (pp. 174-178).

Partiendo de este estudio empírico, Lindemann extrae la conclusión teórica general de que en la relación diádica entre Ego y Alter, Alter sólo será un actor social legítimo -y por tanto la interacción entre Ego y Alter sólo será una relación social propiamente dicha- cuando a través de la relación común de Ego y Alter con un tercero, se determine que Alter tiene que ser reconocido como un actor social. El tercero significaría así la obligación para el reconocimiento de Alter como actor social o bien su deslegitimación como tal actor social (pp. 178ss).

De este modo se haría comprensible la determinación de los "límites de lo social" -que constituye el problema teórico general de Lindemann-, límites que no tendrían por qué coincidir a priori con los de lo humano. Así, hay sociedades en las que también se reconocen como actores sociales legítimos a las plantas, los animales o los muertos (pp. 169-171). Naturalmente, hemos de suponer que en dichas sociedades los criterios empíricos establecidos para la cualificación como actor social serán distintos de los de la unidad neurológica estudiada por Lindemann -ya que no parece en principio que las plantas sean capaces de utilizar símbolos.

Schürmann (2010), por su parte, nos muestra la otra cara de esta atribución empírica del reconocimiento al oponer nuestra época histórica, en la que "todos los ejemplares nacidos del género homo sapiens valen incuestionablemente como personas", a la de la polis griega, en la que esto no ocurría respecto de las mujeres, los niños, los esclavos y los bárbaros (pp. 85-86). Así, de igual modo que las plantas pueden ser a priori actores sociales legítimos -y de hecho lo son según Lindemann en algunas sociedades- así también ocurre que no todos los seres humanos tienen por qué serlo a priori -y así acontece en efecto en algunas sociedades.

De este modo, la concepción de la atribución empírica del reconocimiento de Lindemann y Schürmann introduce una separación entre la condición de persona y la de ser humano: ser persona no es, desde este enfoque empírico, el modo de ser propio del hombre, sino una determinación puramente empírica, que le será o no reconocida en función de cualesquiera criterios empíricos dados. Ciertamente, uno puede después introducir el imperativo moral y/o jurídico de que a todos los seres humanos se les reconozca como personas 6 , el cual pasará entonces a funcionar

\footnotetext{
6 Como hace, en efecto, Schürmann (2010), p. 86.
} 
como criterio empírico en el orden social que así lo establezca. En este caso, será función del tercero corporeizar o personalizar ese nuevo orden social, legitimando desde él a todo ser humano como persona. Pero, por lo que respecta estrictamente a la concepción de la función del tercero de Schürmann y de Lindemann, lo único que cabría hacer es constatar que la atribución de legitimidad por parte del tercero es una cuestión empírica, históricamente determinada (Schürmann 2010, p. 86).

Con su concepción de la atribución empírica del reconocimiento, Lindemann y Schürmann profundizan el carácter empírico del planteamiento clásico. En Berger y Luckmann el tercero ya cumplía la función de personalizar el orden normativo, en cuanto que, al objetivar la norma, hacía que ésta se presentara ante los actores de la díada como "un hecho exterior y coercitivo" al que debían plegar sus acciones (Berger y Luckmann 2011, p. 78). Sin embargo, quién fuera persona social estaba determinado de antemano y pertenecía, junto con el problema de la constitución de las normas como normas, a otro orden de cuestiones que escapaba al dominio de la teoría social. La razón es clara; y es que la cuestión de la condición personal de los sujetos coincide con el problema filosófico-trascendental de la condición normativa de las normas, si por persona entendemos -como implícitamente hacen Berger y Luckmann- justamente aquel sujeto que se encuentra referido a normas o que es capaz de regir sus acciones de acuerdo con normas. Así, Robinson y Viernes son ya personas cuando comienzan a interactuar, y sólo por ello pueden crear normas en el curso de su interacción (Berger y Luckmann 2011, p. 75). Ahora bien, como hemos visto, el modo como Berger y Luckmann evitaban presentar la condición normativa de las normas $-\mathrm{y}$, con ella, la condición personal de los sujetos- como empírica resultaba muy ambiguo y, en esa misma medida, inestable. Lo que hacen Lindemann y Schürmann es resolver ya decididamente esa ambivalencia en favor de lo empírico, sometiendo la determinación de la legitimidad como persona social al propio orden social normativo vigente en cada caso, considerado a su vez exclusivamente como algo empírico.

Pues bien, con esta profundización del planteamiento empírico de la función del tercero se pone por fin de manifiesto el verdadero límite interno de la "teoría social triádica" en cuanto que perteneciente a la sociología concebida como disciplina empírica, pues la función empirica que se le atribuye al tercero, en la medida en que conduce a una separación entre la condición de persona y la de ser humano, se reduce a si misma al absurdo, ya que sólo los seres humanos pueden situarse en la posición del tercero. Así, la función del tercero sería la de determinar empíricamente qué entidades son personas -lo cual no podría determinarse a priori-, pero la propia idea de una tercera posición estará ya presuponiendo una determinada entidad: justamente aquella caracterizada de antemano por su capacidad de ocupar dicha posición del tercero. En la medida en que esa entidad sólo puede ser un ser humano, la presuposición antropológica que todo el planteamiento tenía por fin evi- 
tar se cuela por la puerta de atrás en su mismísimo centro: el tercero, que tenía que servir a evitar la presuposición antropológica, constituye él mismo una presuposición antropológica.

En efecto, la misma Lindemann hace notar -aunque ciertamente sólo como de pasada- algo que de todos modos se sigue necesariamente de su concepción de la función del tercero, a saber, que la obligación al reconocimiento que significa el tercero rige para todos los actores de la tríada (Lindemann 2010, p. 162). Pero entonces, esto supone que las posiciones Ego, Alter y Tertius deberían poder ser adoptadas por todos los implicados. Ahora bien, esta rotación de las posiciones no parece posible respecto de plantas, animales o muertos. Más bien, lo que ocurre es que las sociedades que reconocen a estas entidades como actores sociales legítimos son precisamente sociedades de humanos, ocupando siempre en ellas las plantas, los animales o los muertos, en el tipo de constelación social propuesta por Lindemann, la posición de Alter, esto es, la posición de aquello que resulta socialmente reconocido. Lo que ni se da ni puede darse -justamente porque las plantas no son capaces de establecer relaciones sociales triposicionales- es una sociedad de plantas en la que éstas, ocupando la posición de Ego y de Tertius, reconozcan a un ser humano en posición de Alter como actor social legítimo. Pero entonces, en aquellas sociedades que reconocen aparentemente a las plantas como actores sociales legítimos, el tipo de relación social que pueda establecerse con ellas no se encontrará nunca en pie de igualdad con la relación social que en esas mismas sociedades se establezca entre seres humanos -por tanto, no será una relación social de la misma especie, o lo que es lo mismo, no será una relación social personal en sentido propio.

De este modo, el planteamiento de Lindemann y de Schürmann profundiza la dificultad que ya se nos había aparecido en la concepción de Berger y Luckmann, a saber: que el tercero apunta a un problema trascendental que está más allá del alcance del planteamiento teórico-social en cuanto que empírico. El planteamiento empírico no puede mantenerse ante el hecho - ese hecho tan particular- de que el modo de ser propio del hombre - $\mathrm{y}$, de entre todas las entidades por nosotros conocidas, sólo de él- sea ser persona, y por consiguiente estar referido a normas. El carácter empírico del enfoque teórico-social de la función del tercero conduce a una contradicción con este "hecho".

Ahora bien, si el tercero tiene, como propondremos a continuación, una función constitutiva en sentido trascendental respecto de la propia condición de persona, la cual no constituye a su vez sino el peculiar modo de ser de una entidad determinada, lo que tenemos que mostrar es cómo esa entidad, que es el ser humano, llegó a su ser. Evidentemente, no se tratará aquí de reducir el problema a una cuestión meramente -abstractamente- filogenética, con la que nos limitaríamos absurdamente a sustituir una empiria por otra. Desde una consideración abstractamente filogenética jamás se logrará dar cuenta del modo de ser del hombre en su especifici- 
dad propia, pues por su carácter empírico, esa consideración no permite nunca hacerse cargo de la irrupción de la novedad radical humana, que supone un modo de ser irreductible ya a las condiciones biológico-genéricas de partida. Sin embargo, no es menos cierto que dichas condiciones biológico-genéricas son las condiciones genéticas a partir de las cuales puede llegar a tener lugar esa novedad, y que, por lo mismo, dichas condiciones biológico-genéricas previas siguen dándose en el ser humano, sólo que transformadas a una nueva escala específica -y es justamente sólo por este seguir dándose por lo que puede haber y siempre habrá intentos de dar cuenta de la antropogénesis en términos abstractamente filogenéticos.

Pues bien, la propuesta que vamos a hacer a continuación es la de que el tercero, o la tercera posición personal -como preferiremos denominarla en lo que sigue-, sería el tema de la antropología filosófica, en cuanto que proporcionaría la clave de la constitución -en sentido trascendental- del modo de ser del hombre a partir de -en sentido filogenético- las condiciones genérico-vivientes de las que parte, y que permanecen como una condición genérica que sigue dándose, sólo que ahora a una nueva escala específica.

La idea de la tercera posición ha sido propuesta por Juan B. Fuentes como la clave que podría permitir culminar, en la forma de una antropología filosófica, el proyecto orteguiano de casar vida con razón (Fuentes 2011). En su núcleo básico, la "tercera posición" consiste en la siguiente estructura:

La estructura topológica tri-posicional que adquiere la vida social cuando ocurre que para cualesquiera dos individuos operatorios cuyos cuerpos y operaciones sean mutuamente perceptibles, sea preciso sin embargo contar, y como condición interna necesaria de la prosecución de sus interrelaciones operatorias (en principio, de sus co-operaciones), con las operaciones de algún otro tercer individuo operatorio cuyo cuerpo y operaciones no puedan estar, de entrada por razones geográfico-físicas, presentes en el espacio perceptivo y operatorio de los dos primeros (Fuentes 2010, p. 66).

Sin embargo, a diferencia del desarrollo que este autor ha llevado a cabo hasta ahora de esta idea en sus posteriores escritos, el cual se ha encontrado dirigido a la consecución -en la estirpe orteguiana de una filosofía de la razón vital e histórica, en efecto- de una filosofía de la historia caracterizada por la oposición entre la comunidad universal efectivamente sostenida por el Imperio católico español -de estructura precisamente triposicional, en cuanto que internamente animada por el dogma trinitario- y la universalidad abstracta económico-técnica propia de la modernidad (Fuentes 2013), en el próximo apartado, dando un paso atrás, nuestro esfuerzo va a ir dirigido a la explicitación del sentido lógico-trascendental de esta estructura triposicional y del modo como ella supone una transformación a escala específicamente humana de la espacialidad y de la temporalidad zoológicas -y, por tanto, a la explicitación de lo contenido en forma nuclear en el pasaje anteriormen- 
te citado de Fuentes 2010 y asumido y ejercido de manera efectiva en el marco de la mencionada filosofía de la historia.

\section{La tercera posición personal como condición trascendental de posibilidad de lo humano}

Se trata, como decíamos, de dar con la estructura que permita entender la constitución del modo de ser específico del hombre a partir de sus condiciones genérico-vivientes previas. En particular, partiremos filogenéticamente, en términos muy generales, de un organismo conductual que desarrolla su acción conductual en unas determinadas espacialidad y temporalidad zoológicas, a la vez que transforma a través de dicha acción su medio entorno. Respecto de este espacio, este tiempo y esta modificación zoológica del medio, se alcanza en cierto momento una determinada estructura topográfica, justamente triposicional, a partir de la cual esas condiciones zoológicas quedan refundidas a una nueva escala. De este modo, la relación entre las condiciones zoológicas previas y lo que esta estructura produce a partir de ellas es de transformación por refundición y no de continuidad. La causa genética que haya podido conducir a esta estructura no nos interesará aquí. Se tratará, en todo caso, de una causa o de una pluralidad de causas a las que la estructura no se reducirá una vez constituida.

\subsection{La espacialidad del ser humano: la ausencia re-presentada de la tercera posición}

Por sus condiciones zoológico-genéricas, el hombre vive en un espacio caracterizado por relaciones de distancia que las distintas cosas materiales de su ambiente tienen entre sí respecto de su cuerpo en acción, a la vez que se dan también relaciones de presencia y ausencia, en cuanto que las cosas percibidas tienen lo que la psicología de la Gestalt denominó figura y fondo (Fuentes 2003 y 2010). Sin embargo, la estructura topográfica triposicional supone una nueva determinación del espacio, con una dialéctica entre presencia y ausencia específicamente distinta de la dialéctica entre figura y fondo.

En efecto, los sujetos A y B se encuentran presentes, tanto en el sentido de la presencia actual -entendida como la continuidad temporal de una acción-como en el de la mutua comparecencia o perceptibilidad. Respecto de esta presencia en la que se encuentran A y B, los sujetos C y D se encuentran ausentes, ocupan un lugar en el espacio que no es el lugar en el que están A y B, no comparecen para A y B. Esta ausencia de $\mathrm{C}$ y D supone la apertura de la posibilidad de que las acciones u operaciones de A y B se interrelacionen entre sí por una referencia conjunta a las 
operaciones de C y D -a su vez coordinadas entre sí por una referencia conjunta a las operaciones de A y B. Se trata, por tanto, de una estructura topográfica que, en cuanto que triposicional, supone una interrelación o coordinación específica de las acciones productivas.

Ahora bien, para que esta interrelación de las acciones de A y B tenga lugar por una referencia conjunta a las acciones de $\mathrm{C}$ y $\mathrm{D}$, será preciso que $\mathrm{A}$ re-presente ante $\mathrm{B}$, o viceversa, las acciones ausentes, y por ende no percibidas, de C y D. De este modo, el lenguaje constituye una condición interna para el logro de este tipo específico de interrelación triposicional. Esta re-presentación lingüística resulta posible en virtud de la presencia en la que se encuentran A y B. Así, A puede representar ante $\mathrm{B}-\mathrm{O}$ la recíproca- situaciones extralingüísticas por medio del lenguaje, en cuanto que su discurso resulta susceptible de ser percibido por B. Asimismo, A se dirige a $\mathrm{B}$, le apela, en segunda persona, mientras que habla de sí mismo en primera persona.

Respecto de esta presencia en la que se encuentran A y B, la ausencia de C y D significa que A y B ni pueden apelarles ni pueden representar ante ellos situaciones extralingüísticas, ya que sus palabras no resultan susceptibles de ser percibidas por ellos. En la medida en que A y B tienen en cuenta las acciones de C y D -lo cual resulta necesario para que se logre la coordinación de sus acciones-, se refieren a ellos en tercera persona. A su vez, las acciones de C y D transcurren para A y B de una manera distinta a como lo hacen su propias acciones. Esta diferencia se puede apresar conceptualmente recurriendo a la distinción lingüística entre los modos verbales indicativo y subjuntivo.

En efecto, mientras que lo que acontece en la presencia es constatable, lo que pueda estar o no aconteciendo en la ausencia es algo sobre lo que en principio sólo cabe emitir hipótesis. Por ello, para A y B su acción acontece en un modalidad indicativa, mientras que la acción de C y D lo hace en una modalidad subjuntiva. Así, de manera escolar, podríamos definir la modalidad de la enunciación como la actitud del hablante ante lo que dice al oyente. Así mismo de manera escolar, el modo indicativo suele definirse como aquel que usa el hablante cuando se compromete con la realidad del hecho, cuando lo constata, mientras que el subjuntivo es el modo de la posibilidad, de la hipótesis, la conjetura o el deseo (González 1995).

Ahora bien, como es sabido, los modos indicativo y subjuntivo en que transcurre la acción se reflejan en la flexión verbal junto con la persona y el tiempo. ¿Cómo cabrá entender este tiempo en su relación con la persona y el modo?

\subsection{La temporalidad histórica del ser humano y el carácter específicamente humano de la producción}

Las acciones de los animales, que no tienen relaciones personales ni, por tanto, modalidades indicativa y subjuntiva de la acción, tienen lugar en una determinada 
temporalidad, en cuanto que, en función de la acción que están llevando a cabo, son capaces tanto de recordar acciones y situaciones pasadas como de anticipar por medio de la imaginación situaciones en lo que éstas puedan tener de novedosas (Fuentes 2003 y 2010). Pero esta temporalidad del animal es una temporalidad limitada siempre a la continuidad de su acción y debe ser netamente distinguida de la temporalidad especifica del ser humano, que se encuentra modificada en virtud de la doble modalidad indicativa y subjuntiva de la acción. Así, C y D introducen para A y B la dimensión temporal de un pasado y un futuro -y con ellos también de un presente- que trascienden la continuidad temporal de la acción zoológica.

En efecto, A y B esperan que en su propio futuro -el futuro de su propia modalidad indicativa - la acción de $C$ y D haya tenido lugar; y lo esperan porque sólo así su propia acción -la de A y B- cobrará sentido - de otro modo estará incompleta, habrá sido en vano. De este modo, en virtud de su referencia a $\mathrm{C}$ y $\mathrm{D}$, de la aspiración a coordinar su acción con la acción de $\mathrm{C}$ y $\mathrm{D}$, se abre para $\mathrm{A}$ y $\mathrm{B}$, en el seno de su propia acción, un futuro que trasciende el tipo de temporalidad continua que tiene la acción meramente zoológica. Ahora bien, la acción de $\mathrm{C}$ y D es necesaria para que la acción de A y B tenga sentido, pero nótese que A y B no realizan su acción confiando en que en el futuro presenciarán la acción de $\mathrm{C}$ y $\mathrm{D}$, sino confiando en que en su propio futuro -el futuro de indicativo de A y B- la acción de C y D haya tenido lugar. Así, cuando C y D devienen presentes - en el encuentro con ellos, es decir, cuando pasan a ser segunda persona- su acción ya ha tenido lugar, quedando su producto, aquello que ella ha llevado a efecto, mientras que entretanto $\mathrm{C}$ y D no devienen presentes su acción se espera. Es importante asimismo notar que desde el punto de vista de C y D, A y B son la tercera persona, circunstancia de la que A y B son conscientes y que constituye la condición de la coordinación de sus acciones. Por ello, A y B no sólo esperan que C y D lleven ante ellos el resultado de su acción, sino que conservan asimismo el resultado de su propia acción para cuando lleguen $\mathrm{C}$ y D. Cuando todos ellos se juntan, sus acciones ya han pasado, y lo que permanece son sus resultados objetivados.

De este modo, la estructura triposicional de las relaciones humanas implica un tipo de temporalidad, irreductible a la temporalidad de la vida animal, consistente en un pasado y un futuro discontinuos respecto de la unidad temporal de cualquier acción en cuanto que esta acción cuenta siempre con los resultados objetivados tanto de acciones pasadas como de acciones futuras que se anticipan. Se trata, por tanto, de una temporalidad ya intrínsecamente histórica.

\subsection{El carácter normativo de la cultura como condición de la temporalidad específica en cuanto que histórica del ser humano}

Ahora bien, para que pueda llegar a tener lugar la coordinación de las acciones entre las posiciones primera y segunda, co-presentes en un "aquí y ahora", y la ter- 
cera, ausente, resulta preciso que se produzca una formalización de las acciones, la cual a su vez reobra sobre la propia estructura triposicional, sirviendo a su mantenimiento. En efecto, para que A y B puedan coordinar sus acciones con las acciones no percibidas de $\mathrm{C}$ y D, A y B, como hemos visto, deben re-presentarse recíprocamente dichas acciones, lo cual tiene lugar en subjuntivo. Pero a la vez, por lo mismo, si las acciones de la tercera persona estuvieran dejadas a cualquier albur, A y B no podrían conjeturarlas adecuadamente. De este modo, cuando C y D devinieran presentes, serían muchas las posibilidades -demasiadas- de que el resultado de sus acciones no pudiera entrelazarse como debiera con el resultado de las acciones de A y B. Por ello, de la propia necesidad de este entrelazamiento de los productos de las acciones de la primera y la segunda posiciones con la tercera resulta la exigencia de que las acciones de ambas -recordemos que la estructura es relativa: para C y D los sujetos A y B son la tercera persona- estén formalizadas, esto es, acontezcan precisamente de acuerdo a una norma que posibilite su misma coordinación. Esta formalización de las acciones tiene lugar en virtud de la propia morfología tanto de los objetos con los que se construye y que se usan, como de los objetos que se construyen. Pero entonces, lo que esto significa es que la norma de construcción y de uso de cada objeto - el concepto de cada objeto, esto es, la organización estructural y funcional que se imprime a los materiales de la naturaleza- es posterior -en sentido lógico-respecto de la norma de su coordinación con los otros objetos; y, por tanto, que las acciones individuales - de construcción y de uso de objetos individuales- de un determinado sujeto se encuentran normativizadas en cuanto que están conjugadas con las acciones individuales de otros sujetos. A su vez, la naturaleza aparece sólo como los materiales de la cultura $-y$ no por tanto en sí, signifique esto lo que signifique-, que en cuanto que materiales están -como lo están los fonemas de una determinada lengua- ya formalizados.

Lo que se produce propiamente en las relaciones triposicionales no son normas, sino los distintos objetos de la cultura de acuerdo con normas. Pero entonces, lo que se sigue de todo lo dicho es que la propia trascendencia de la cultura humana más allá del "aquí y ahora" depende de las normas. La conservación -y la re-producción- de los objetos de la cultura depende como se ha visto de la estructura topológica triposicional, pero ésta sólo llega a constituirse en cuanto que mediada por normas. De este modo, precisamente en la medida en que la norma como norma, en su condición normativa, se encuentra como los teoremas matemáticos al margen del tiempo -sin perjuicio de que una norma que no esté vigente sencillamente no exista-, ella es la que posibilita la propia historicidad de la cultura y, con ella, asimismo -como hemos visto- la propia temporalidad específica - específicamente distinta de la del animal- de la vida humana. 


\subsection{La condición de persona como modo de ser propio del hombre}

Ahora bien, la estructura topográfica triposicional de las relaciones humanas, en cuanto que constituye trascendentalmente la cultura humana -cuyo carácter es normativo- constituye asimismo trascendentalmente la condición de persona de los sujetos -si por persona entendemos aquel sujeto que orienta sus acciones de acuerdo con normas. Este sujeto que es persona será necesariamente también-según lo que acabamos de ver- un sujeto orgánico cuyo mundo ya no resultará co-genérico con el medio entorno de los sujetos orgánicos meramente zoológicos, habida cuenta de sus especificas espacialidad, temporalidad y estructura normativa. La condición de persona es indisociable de este específico modo de ser de estos sujetos orgánicos tan sumamente peculiares que son los seres humanos.

Si no supiéramos que el ser humano desciende de sujetos orgánicos meramente zoológicos bastaría con constatar la diferencia. Aun así, podríamos seguir apreciando el peculiar escalonamiento -si podemos decirlo así-, de la realidad, donde cada escalón sucesivo mantiene a los anteriores, aunque sometidos a su nueva escala específica: de la materia sólo física pasamos a la vida sólo fisiológica -que también es material-, de ésta a la vida conductual -que también es fisiológica-y, por fin, a la vida humana -dada, entre otras cosas, en unas espacialidad y temporalidad específicas que refunden a una nueva escala la espacialidad y la temporalidad propias de la acción conductual zoológica. Sin embargo, sabemos además que el ser humano proviene o desciende del animal. No podemos hacer aquí siquiera un esbozo mínimo de antropogénesis. Lo único importante a los efectos de este trabajo es notar que será la propia estructura triposicional de las relaciones entre determinados sujetos orgánicos - cuya formación tendrá lugar por refundición de cursos genéticos previos a los que ella no se reducirá una vez constituida- aquélla en virtud de la cual el ser humano podrá empezar a constituirse a la vez como "homo sapiens" y como persona, en su hominitas y su humanitas -siendo ambas determinaciones en realidad, de acuerdo con todo lo que hemos visto, una y la misma. Esta concepción de la antropogénesis obviamente exigirá contar con una teoría de la evolución más compleja que la denominada "teoría sintética" o darwinismo ortodoxo, que permita comprender cómo la evolución orgánica está dirigida por las acciones innovadoras de los propios organismos en sus medios y por sus modificaciones sobre ellos. Al respecto nos limitaremos a mencionar aquí el conocido "Efecto Baldwin" (Baldwin 1896) y una teoría reciente más comprensiva, la "Niche Construction Theory" (OdlingSmee, Laland y Feldamn 2003), que vienen proponiendo en los últimos años diversos biólogos como un marco comprensivo para la evolución -que incluiría por cierto a la conocida "Evo-Devo" o Biología Evolutiva del Desarrollo (Laland, OdlingSmee y Gilbert 2008)-, y ello sin perjuicio de que la concepción de la antropogénesis de los proponentes de esta teoría siga siendo continuista o biologicista -por 
carecer justamente de la idea de tercera posición, y por tanto del criterio para la novedad radical de lo humano.

"Ser persona" es, en definitiva, desde la idea antropológico-filosófica de la tercera persona, el modo de ser del ser humano, y no, como ocurría en el planteamiento teórico-social -en la versión de Lindemann y Schürmann- una determinación empírica que pueda atribuirse empíricamente a unas u otras entidades -sean o no seres humanos, y pudiendo incluso llegar a excluir a determinados seres humanos.

\section{Las dos posibles versiones de la yuxtaposición entre la hominitas y la humanitas}

Es de todo punto esencial notar que la estructura topológica tri-posicional hace posible-trascendentalmente- la cultura humana, cuya estructura es normativa, pero esta cultura no es su obra, sino que lo es de los cuerpos singulares -que viven en unas condiciones históricas particulares-, en cuanto que situados en esas relaciones tri-posicionales. Esto significa que, si bien la propia condición normativa de la cultura es necesaria a priori -es decir, que allá donde haya cultura humana, ésta tendrá necesariamente una estructura normativa-, las normas como tales no se deducen desde luego de la estructura tri-posicional, de modo que en cada situación histórica dada habrá unas normas determinadas y particulares. A su vez, así como la condición de persona de los sujetos es correlativa a la condición normativa de la cultura -y es por tanto una determinación a priori: el modo de ser del hombre-, así, del mismo modo, correlativamente con las normas particulares lo que hay son roles sociales determinados para los que algunos individuos estarán cualificados y otros no -según lo que se encuentre previsto por las normas.

\subsection{La reducción sociológica de la condición de persona al rol social}

Pues bien, lo que hace la teoría social aquí considerada es reducir la condición normativa de la cultura a lo que en ésta es particular y variable -con lo que las normas se convierten en algo meramente empírico- $y$, correlativamente, la condición personal de los sujetos a los roles sociales determinados - con lo que dicha condición personal se convierte también en algo meramente empírico. Es preciso darse cuenta de que no se trata de que la teoría social sólo se quede con un aspecto, pues es justamente esta "sustracción" la que no es legítima: es ella misma la que genera "lo empírico". Así, no se trata de que las normas tengan una "parte" empírica y otra "parte" trascendental. Uno no es persona en relación con la condición normativa de la cultura y, por otra parte, desempeña un rol social definido por las normas particulares; sino que, más bien, se es y sólo se puede ser persona in medias res, en relación con normas que son siempre necesariamente normas particulares, $\mathrm{y}$, por tanto, desempeñando determinados roles sociales. 
Esta concepción de la persona como modo de ser del hombre debe ser mantenida frente a la concepción empírica de la persona propia del planteamiento teóricosocial de la función del tercero. Recordemos la forma que éste adoptaba en la propuesta de Volker Schürmann. Este autor oponía dos circunstancias históricas: la actual, en la que todos los seres humanos son reconocidos como personas, y una situación pretérita en la que éste no era el caso. Ahora bien, la categoría de persona, que significa en cada una de estas situaciones históricas algo diferente, conduce en todo caso en ambas, como lo ha mostrado Roberto Esposito (2009)7, a una separación entre el derecho y la vida; entre la condición de persona y la de homo sapiens. Tomando el derecho romano como referente histórico de una situación en la que no todos los seres humanos eran reconocidos como personas, Esposito muestra cómo en este marco jurídico la "idea de persona (...) es la categoría más general dentro de la cual se disponen todas las otras, mediante un juego de bifurcaciones consecutivas que del género lleva a la especie, sin detenerse nunca en el hombre particular", siendo la primera división la que distingue entre esclavos y libres, con la paradójica situación de que el esclavo "es literalmente la no-persona dentro de la categoría más general de persona" (Esposito 2009, pp. 114-115).

Ahora bien, esta distinción entre seres humanos que son persona -los libres- $\mathrm{y}$ seres humanos que sólo son seres humanos - los esclavos, que son "la cosa viviente o la vida encerrada en la cosa" (Esposito 2009, p. 115)- depende de tomar la categoría de persona por una determinación óntica, como se corresponde con el esquema de géneros y especies o de categorías cada vez más abstractas que esboza Esposito. Se trata, según lo que hemos visto aquí, de la reducción de la persona en sentido trascendental a la persona en sentido meramente empírico, lo cual supone inversamente una extralimitación del lugar que les corresponde a las normas particulares que median en cada caso las relaciones interpersonales, las cuales incluyen en efecto siempre una tipología de los actores $-\mathrm{o}$ de los roles sociales- (Berger y Luckmann 2011, pp. 93ss.), pero no determinan qué entidades deben o no ser reconocidas como personas.

\subsection{Razón y naturaleza: la universalidad negativo-abstracta de los indivi- duos aislados frente a la universalidad inmanente concreta y perspecti- vista de la tercera posición}

Por su parte, la separación entre el derecho y la vida que introduce la categoría de persona en la modernidad tiene que ver, según Esposito, con que "la persona deja

\footnotetext{
${ }^{7}$ Nos referimos a la idea de Esposito de que la categoría de persona introduce tanto en el derecho romano como en el moderno una separación entre la condición de persona y la de mero ser humano. Esto no obsta para que, sin embargo, no sigamos ya a este autor en su propuesta de superar aquella separación interpretando la "tercera persona" como lo "impersonal".
} 
de ser una categoría general en cuyo interior se puede transitar, entrando y saliendo, como ocurría en Roma, para convertirse en un predicado implícito en cada hombre", con lo que "ella se revela distinta y superpuesta al sustrato natural sobre el que se implanta. Tanto más cuanto que se identifica con la parte racional-voluntaria o moral -es decir, dotada de valor universal- del individuo" (Esposito 2009, p. 122).

Desde el punto de vista de la idea antropológico-filosófica de la tercera persona que aquí hemos defendido, esta separación entre una parte racional-voluntaria y un sustrato natural se debería a que, si bien la persona sí se toma en este caso en un sentido trascendental, se la abstrae de la dimensión relacional y, con ello, del carácter concreto de los contenidos culturales normativos que median siempre, en cada situación histórica, las relaciones humanas. En efecto, la universalidad que se atribuye a la persona individual en su aislamiento -como "un predicado implícito en cada hombre", según lo expresaba Esposito- conduce a una universalidad puramente negativo-abstracta en las relaciones entre los individuos, siendo ésta la que en última instancia explica que los fundamentos de determinación de la voluntad hayan de aparecer como meramente naturales. Pues, en efecto, el carácter abstracto de las relaciones excluye la posibilidad de contenidos comunes o compartidos que las medien, cuando son estos contenidos comunes -la cultura histórica concreta que comparte una comunidad humana- los que, por su carácter común, esto es, por ser producto de los hombres en sus relaciones mutuas, constituyen fundamentos de determinación de la voluntad elevados por encima de lo meramente natural. Por el contrario, la concepción de la persona que aquí hemos propuesto cifra la dimensión trascendental de la persona en lo relacional, lo cual supone que el sujeto personal es aquel que se relaciona con otros necesariamente siempre a través de determinados contenidos culturales compartidos. Esto significa, a su vez, que la universalidad de la persona no es en este caso negativo-abstracta, sino que se trata de una universalidad inmanente concreta o perspectivista. Para ver en qué consiste esta universalidad inmanente tenemos antes que mostrar cómo la reciprocidad de las relaciones humanas depende de la tercera posición personal.

Resulta esencial notar que la reciprocidad de la relación diádica incluye como momentos funcionales suyos no sólo al otro y a mí mismo, sino además a aquello que ambos nos llevamos conjuntamente entre manos, esto es, al contenido de nuestra relación. De este modo, la reciprocidad es siempre relativa a un contenido común que existe entre A y B. A su vez, para A, ese contenido común es propio no únicamente porque sea común, sino asimismo porque ella puede hacer un uso individualmente determinado de él, pero -y esto es esencial- ese uso individualmente determinado está siempre conjugado, en el marco de la relación recíproca, con el uso a su vez individualmente determinado que de ese contenido o de otros contenidos normativos interrelacionados con él esté haciendo asimismo B. Ahora bien, lo que hemos visto es que ese contenido común de la relación diádica sólo se consti- 
tuye -trascendentalmente- por la referencia común que A y B tienen respecto de los resultados de las acciones que $\mathrm{C}$ y $\mathrm{D}$ estén llevando a cabo en una tercera posición.

Pero entonces, en la medida en que la relación de reciprocidad entre los miembros de una comunidad cultural determinada no es una relación inmediata, sino mediada por los contenidos comunes que se comparten, toda comunidad cultural humana se encuentra por principio constitutivamente abierta al tercero. Así, el contenido común que existe entre A y B, en virtud del cual se configura su reciprocidad, es un contenido que potencialmente, en cualquier momento, puede llevar a que A o B establezcan sobre su base una relación recíproca con cualquier $\mathrm{C}$ posible $-\mathrm{y}$ no sólo de su propia esfera cultural, sino virtualmente de cualquier otra. Se trataría, así, de una universalidad inmanente perspectivista en cuanto que propagación recurrente ilimitada de las relaciones interpersonales recíprocas, la cual tiene como su condición la propagación de los propios contenidos normativos en torno a los cuales se establece la reciprocidad de las relaciones. Esta propagación tendría lugar como un entrelazamiento de lugares humanos inicialmente aislados, logrado en cada punto a través de una criba inmanente de las normas particulares de los distintos lugares humanos que así se encontraran, criba sin la cual resultaría imposible el establecimiento de una verdadera reciprocidad interpersonal.

Esta dialéctica puede verse sin embargo bloqueada -y acaso tienda inercialmente a verse bloqueada- en el momento en el que, por las razones que fueren, se extralimiten las normas particulares que determinan roles sociales en perjuicio del sentido trascendental de la condición de persona -como habría ocurrido en el Imperio Romano- o, a la inversa - como ocurriría en la modernidad-, el sentido trascendental de la condición de persona, al atribuirse a la persona aislada y no a la dimensión relacional, deslegitime el carácter siempre necesariamente particular y común o compartido de los contenidos culturales normativos, que pasan así a considerarse como meramente empíricos. En ambos casos, como se ha visto, esto tiene como consecuencia la producción de una yuxtaposición entre el derecho y la vida, entre la condición de persona y la de homo sapiens, que no se daría en el caso de que se sostuviera -teórica y práctica o históricamente- el sentido trascendental de la condición personal en cuanto que dependiente siempre de la dimensión relacional triposicional.

\section{Referencias bibliográficas}

BALDwIN, J.M. (1896): “A New Factor in Evolution”, The American Naturalist, 30 (354), pp. 441-451.

Bedorf, T., J. Fischer, y G. Lindemann (eds.) (2010): Theorien des Dritten. Innovationen in Soziologie und Sozialphilosophie, München, W. Fink. 
Berger, P.-L. y T. LuCKMANN (2011): La construcción social de la realidad, Buenos Aires, Amorrortu.

Esposito, R. (2009): Tercera persona. Política de la vida y filosofía de lo impersonal, Buenos Aires, Amorrortu.

Eßlinger, E., T. Schlechtriemen, D. Schweitzer y A. Zons (eds.) (2010): Die Figur des Dritten. Ein Kulturwissenschaftliches Paradigma, Berlin, Suhrkamp. Fischer, J. (2000): "Der Dritte. Zur Anthropologie der Intersubjektivität”, en W. Eßbach (ed.), Wir / ihr / sie. Identität und Alterität in Theorie und Methode, Würzburg, Ergo, pp. 103-136.

Fischer, J. (2006): "Der Dritte/Tertiarität. Zu einer Theorieinnovation in den Kultur- und Sozialwissenschaften", en G. Lindemann y H.P. Krüger (eds.), Philosophische Anthropologie im 21. Jahrhundert, Berlin, Akademie Verlag, pp. 146-163.

FiscHER, J. (2010): “Tertiarität / Der Dritte. Soziologie als Schlüsseldisziplin”, en T. Bedorf [et al.] 2010, pp. 131-159.

FuENTES, J.B. (2003): "Intencionalidad, significado y representación en la encrucijada de las “ciencias" del conocimiento", Estudios de Psicología, 24 (1), pp. 33 90.

Fuentes, J.B. (2010): "La teoría del origen trófico del conocimiento de Ramón Turró. Un ensayo sobre su trasfondo histórico-filosófico y sus posibilidades de desarrollo teórico en el sentido de una concepción (neo)aristotélica de la vida, Psychologia Latina, 1 (1), pp. 27-60.

Fuentes, J.B. (2011): "Proyecto Docente de las asignaturas de Antropología filosófica I y II", Madrid, E-Prints Complutense: http://eprints.ucm.es/17643/ (17 de enero de 2013).

Fuentes, J.B. (2013): "Entrevista: Política, Metapolítica y Modernidad. El caso de España”, Madrid, E-Prints Complutense: http://eprints.ucm.es/23436/ (17 de diciembre de 2013).

GonzÁlez Calvo, J.M. (1995): "Sobre el modo verbal en español”, Anuario de Estudios Filológicos, 18, pp. 177-203.

Koschorke, A. (2010): “Ein neues Paradigma der Kulturwissenschaften”, en E. Eßlinger [et al.] 2010, pp. 9-34.

LALAND K.N., J. Odling-Smee Y S.F. Gilbert (2008): "EvoDevo and niche construction: building bridges", Journal of Experimental Zoology (Mol. Dev. Evol.), 310B, pp. 549-566.

LindemanN, G. (2010): "Statt der Dyade: die Ego-Alter-Tertius Konstellation als konstitutive Bedingung von Sozialität”, en T. Bedorf [et al.] 2010, pp. 161-188.

LiTT, T. (1926): Individuum und Gemeinschaft. Grundlegung der Kulturphilosophie, Leipzig, Teubner.

Odling-SmeE, F.J., K.N. Laland y M.W. Feldman (2003): Niche Construction: The neglected process in evolution, Princeton, Princeton Univ. Press. 
SchÜRmann, V. (2010): “Der/die oder das Dritte?”, en T. Bedorf [et al.] 2010, pp. 73-89.

VV.AA. (2006): Le Tiers. Archivio di Filosofia - Archives of Philosophy, Pisa Roma: Fabrizio Serra editore, 74 (1-3).

Natalia S. García Pérez

Universidad Complutense de Madrid natasgar@filos.ucm.es 